\title{
Genetic alterations of HER genes in chromophobe renal cell carcinoma
}

\author{
WEN HUI WENG ${ }^{1}$, YING TZU CHEN ${ }^{1}$, KAI JIE YU ${ }^{1,2}$, YING HSU CHANG ${ }^{2,3}$, \\ CHENG KENG CHUANG ${ }^{2,3}$ and SEE TONG PANG ${ }^{2,3}$
}

\begin{abstract}
${ }^{1}$ Department of Chemical Engineering and Biotechnology and Graduate Institute of Biochemical and Biomedical Engineering, National Taipei University of Technology, Taipei $10608 ;{ }^{2}$ Division of Urology, Department of Surgery, Chang Gung Memorial Hospital, Taoyuan $33305 ;{ }^{3}$ School of Medicine,

Chang Gung University, Taoyuan 33302, Taiwan, R.O.C.
\end{abstract}

Received March 9, 2015; Accepted December 7, 2015

DOI: $10.3892 / \mathrm{ol} .2016 .4198$

\begin{abstract}
Chromophobe (ch) renal cell carcinoma (RCC) is the 3rd most common subtype of RCC and occurs in 5\% of all RCCs. Although chRCC generally demonstrates more favorable outcomes compared with other subtypes of RCC, there is a 6-7\% probability of tumor progression and metastasis in this disease. The subclassification of a more aggressive subtype of chRCC may be useful for the management of this cancer. The Erb-B2 receptor tyrosine kinase 2 [also known as human epidermal growth factor receptor (HER) 2] gene has been reported to be important in chRCC. The present study aimed to further investigate the abnormalities of the HER family genes and their potential association with chRCC. Fluorescence in situ hybridization was performed on 11 chRCC tissue specimens, and the Spearman's rank correlation coefficient analysis was used to assess the results. The loss of one copy of the HER2 and HER4 genes was observed to be the major alteration of the tumor cells in all chRCC cases. Statistical data indicated that loss of the HER2 gene was strongly correlated with loss of the HER4 gene ( $\mathrm{P}=0.019)$. The findings of previous studies were also combined for analysis, and were consistent with those of the present study. In addition, the amplification of HER 1 was also strongly correlated with the amplification of HER4 $(\mathrm{P}=0.004)$. Furthermore, a high percentage of genetic
\end{abstract}

Correspondence to: Dr Wen Hui Weng, Department of Chemical Engineering and Biotechnology and Graduate Institute of Biochemical and Biomedical Engineering, National Taipei University of Technology, 1, Section 3, Zhongxiao East Road, Taipei 10608, Taiwan, R.O.C.

E-mail:wwhlab@gmail.com

Dr See Tong Pang, Division of Urology, Department of Surgery, Chang Gung Memorial Hospital, 5 Fu-Hsing Street, Kuei Shan Hsiang, Taoyuan 33305, Taiwan, R.O.C

E-mail: pst64lab@gmail.com

Key words: Erb-B2 receptor tyrosine kinase genes, chromophobe renal cell carcinoma, fluorescence in situ hybridization structural rearrangements was observed in HER3 genes, which was significantly associated with amplification of HER2 $(\mathrm{P}=0.005)$. Certain alterations in the HER gene family were also noted as a phenomenom in chRCC. Therefore, the characterization of the underlying aberrant functions of HER genes may be of interest for additional studies in the context of using HER genes to distinguish between RCC subtypes in order to establish improved treatment guidelines.

\section{Introduction}

Chromophobe renal cell carcinoma (chRCC) is the third most common subtype of kidney cancer and accounts for $\sim 5 \%$ of all RCC cases. The 5-year disease-free survival rate of chRCC is reported to be increased compared with that of other RCC subtypes, including clear cell, sarcomatoid and papillary renal cell carcinoma (pRCC) (1). Although the outcomes of chRCC are typically more favorable compared with those of other subtypes, the disease still demonstrates a 6-7\% probability of tumor progression and metastasis (2).

Histologically, chRCC consists of large polygonal cells with a slightly reticulated cytoplasm, and with clear and/or eosinophilic cells $(3,4)$. The similarities between the histological features of chRCC and oncocytoma, a benign tumor of the kidney, may lead to the misdiagnosis of chRCC (5).

A cytogenetic analysis conducted in a previous study revealed an association between chRCC and the loss of chromosomes 1, 2, 6, 10,13, 17 and 21; therefore, such losses may be prominent abnormalities useful for the diagnosis of the disease (6). In addition, differential gene expression has been used to assist in the diagnosis of chRCC. For example, the V-kit Hardy-Zuckerman 4 feline sarcoma viral oncogene homolog (KIT) gene is indicated to be overexpressed in chRCC compared with pRCC (7). Notably, Petit et al (8) reported that the rate of positive KIT expression on immunohistochemical staining was $\sim 90 \%$ in chRCC tissues and $\sim 70 \%$ in oncocytoma tissues. Tan et al (9) used high-resolution single-nucleotide polymorphism profiling to distinguish between chRCCs and oncocytomas, and pathway analyses emphasized the involvement of Erb-B2 receptor tyrosine kinase 2 [human epidermal growth factor receptor (HER) 2] 
signaling in chRCC. However, in the study conducted by Tan et al, the immunohistochemical analysis did not identify a significant difference in extracellular HER2 expression between chRCCs and oncocytomas.

The roles of other HER family genes, including HER1, HER3 and HER4, have not been well studied in chRCC. The present study aimed to investigate the abnormalities of the HER family and assess a potential association with chRCC.

\section{Materials and methods}

Tissue specimens. In total, 11 chRCC specimens from patients diagnosed between 2005 and 2009 were included in the present study, with approval from the Human Subject Research Ethics Committee/Institutional Review Board at the Chang Gung Memorial Hospital (Taoyuan, Taiwan) (IRB No.:101-3236B). The diagnosis and classification of chRCC was confirmed using pathological analysis, according to the histopathological evaluation of paraffin-embedded sections using the pathological tumor-node-metastasis (TNM) staging criteria. All cases were classified as stage I or II on a four-stage scale, with the exception of cases 7 and 8 , which were classified as stage III. All tumors that were $>4 \mathrm{~cm}$ in size were selected (one case $\leq 4 \mathrm{~cm}$ in size). None of the patients exhibited lymph node involvement or metastases. The majority of the patients were diagnosed with low-grade malignancy, grade II tumors, with the exception of cases 8 and 10 (Table I).

Fluorescence in situ hybridization (FISH). Fresh tissues were collected from 11 chRCC patients for FISH analysis. Touch imprint cytology smears were performed on all frozen tumor samples, following fixation in methanol-acetic acid (dilution, 3:1). Dual color probes were prepared for the target genes. To screen for the HER family genes, several bacterial artificial chromosomes (BACs) were selected, according to the National Center for Biotechnology Information or University of California, Santa Cruz databases, and purchased from the Children's Hospital Oakland (Oakland, CA, USA) (Table II). BACs DNA were isolated using the High-Speed Plasmid Mini kit (Geneaid, Taipei, Taiwan), according to the manufacturer's protocol. The DNA were labeled with fluorescent dye by nick translation according to the protocol published by Weng et al (10), in which HER1 (BAC clone no. RP11-14K11, RP11-339F13 and CTD-2199A14) and HER2 (BAC clone no. RP11-94L15) were labeled with Red-deoxyuridine triphosphatase (dUTP) (Enzo Life Sciences, Inc., Farmingdale, NY, USA), and HER3 (BAC clone no. RP11-973D8), HER4 (BAC clone no. RP11-384K20) and chromosome 17q11.2-12 (BAC clone no. RP11-79O4), which is adjacent to chromosome 17 centromere (CEN17) and used as a HER2 control, were labeled with Green-dUTP (Enzo Life Sciences, Inc.) (Table II). Hybridization was performed at $37^{\circ} \mathrm{C}$ for $8-10 \mathrm{~h}$. All probes were homemade and the accuracy and specificity of all probes was confirmed via hybridization onto commercially available CGH Metaphase Target Slides (Abbott Laboratories Inc., Chicago, IL, USA). All images were captured using a Leica DM2500 microscope (Leica Microsystems GmbH, Wetzlar, Germany) with an ASI CCD camera (CCD-1300DS; Applied Spectral Imaging, Ltd., Migdal HaEmtek, Israel), and subsequently analyzed with FISHView EXPO version 5.5 software (Applied Spectral Imaging, Ltd.).
Table I. Clinical features of 11 chromophobe renal cell carcinoma patients.

\begin{tabular}{|c|c|c|}
\hline \multirow[b]{2}{*}{ Variable } & \multicolumn{2}{|c|}{ Patients } \\
\hline & $\mathrm{n}$ & $\%$ \\
\hline \multicolumn{3}{|c|}{ Age at diagnosis, years ${ }^{\mathrm{a}}$} \\
\hline$\leq 53$ & 6 & 55 \\
\hline$>53$ & 5 & 45 \\
\hline \multicolumn{3}{|l|}{ Gender } \\
\hline Female & 3 & 27 \\
\hline Male & 8 & 73 \\
\hline \multicolumn{3}{|l|}{ Cell type } \\
\hline Typical & 7 & 64 \\
\hline Eosinophilic & 4 & 36 \\
\hline \multicolumn{3}{|l|}{ Metastasis } \\
\hline Present & 0 & 0 \\
\hline Absent & 11 & 100 \\
\hline \multicolumn{3}{|l|}{ TNM stage } \\
\hline I & 6 & 55 \\
\hline II & 3 & 27 \\
\hline III & 2 & 18 \\
\hline \multicolumn{3}{|c|}{ Tumor size, $\mathrm{cm}$} \\
\hline$\leq 4$ & 1 & 9 \\
\hline$>4-7$ & 6 & 55 \\
\hline$>7$ & 4 & 36 \\
\hline \multicolumn{3}{|l|}{ Grade } \\
\hline 1 & 0 & 0 \\
\hline 2 & 9 & 82 \\
\hline 3 & 1 & 9 \\
\hline Unknown & 1 & 9 \\
\hline \multicolumn{3}{|l|}{ Necrosis } \\
\hline Present & 3 & 27 \\
\hline Absent & 8 & 73 \\
\hline
\end{tabular}

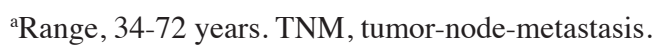

Table II. The tested genes, associated BACs and labeled fluorescent dyes.

\begin{tabular}{lll}
\hline $\begin{array}{l}\text { Gene } \\
\text { name }\end{array}$ & \multicolumn{1}{c}{ BAC } & \multicolumn{1}{c}{$\begin{array}{c}\text { Labeled } \\
\text { dye }\end{array}$} \\
\hline HER1 & $\begin{array}{l}\text { RP11-14K11, } \\
\text { RP11-339F13 and }\end{array}$ & Red-dUTP \\
& CTD-2199A14 & \\
HER2 & RP11-94L15 & Red-dUTP \\
HER3 & RP11-973D8 & Green-dUTP \\
HER4 & RP11-384K20 & Green-dUTP \\
CEN17 & RP11-79O4 & Green-dUTP \\
\hline
\end{tabular}

HER, Erb-B2 receptor tyrosine kinase; CEN17, chromosome 17 centromere; BAC, bacterial artificial chromosome; dUTP, deoxyuridine triphosphatase. 
Table III. Percentage of all HER gene alterations in 11 chromophobe renal cell carcinoma clinical samples using fluorescence in situ hybridization analysis.

\begin{tabular}{|c|c|c|c|c|c|c|c|c|c|c|c|c|c|c|}
\hline \multirow[b]{2}{*}{ Case no. } & \multicolumn{3}{|c|}{ HER 1, \% } & \multicolumn{3}{|c|}{ HER $2, \%$} & \multicolumn{2}{|c|}{ CEN17, \% } & \multicolumn{3}{|c|}{ HER3, \% } & \multicolumn{3}{|c|}{ HER 4, \% } \\
\hline & $\mathrm{L}$ & A & B & $\mathrm{L}$ & A & B & $\mathrm{L}$ & A & $\mathrm{L}$ & A & B & $\mathrm{L}$ & A & B \\
\hline 1 & 2 & 6 & 25 & 78 & 0 & 13 & 94 & 0 & 8 & 4 & 21 & 75 & 0 & 9 \\
\hline 2 & 0 & 6 & 41 & 91 & 1 & 6 & 73 & 2 & 15 & 3 & 30 & 89 & 0 & 6 \\
\hline 3 & 3 & 35 & 18 & 83 & 0 & 9 & 87 & 1 & 10 & 18 & 22 & 69 & 1 & 7 \\
\hline 4 & 5 & 22 & 22 & 76 & 0 & 5 & 74 & 2 & 14 & 7 & 21 & 70 & 1 & 5 \\
\hline 5 & 2 & 34 & 11 & 72 & 0 & 7 & 91 & 0 & 8 & 8 & 24 & 64 & 1 & 7 \\
\hline 6 & 3 & 14 & 28 & 75 & 0 & 7 & 74 & 2 & 4 & 13 & 25 & 79 & 0 & 11 \\
\hline 7 & 5 & 20 & 7 & 88 & 0 & 2 & 86 & 0 & 10 & 3 & 19 & 86 & 0 & 3 \\
\hline 8 & 1 & 16 & 38 & 71 & 1 & 6 & 72 & 1 & 14 & 6 & 26 & 74 & 0 & 10 \\
\hline 9 & 2 & 12 & 21 & 97 & 0 & 2 & 88 & 0 & 15 & 1 & 22 & 77 & 0 & 11 \\
\hline 10 & 7 & 19 & 11 & 83 & 0 & 2 & 86 & 0 & 12 & 9 & 24 & 75 & 0 & 10 \\
\hline 11 & 7 & 21 & 12 & 26 & 9 & 7 & 41 & 6 & 13 & 10 & 28 & 60 & 5 & 5 \\
\hline
\end{tabular}

Gene alterations include: L, loss; A, amplification; B, break-apart. HER, Erb-B2 receptor tyrosine kinase; CEN17, chromosome 17 centromere.
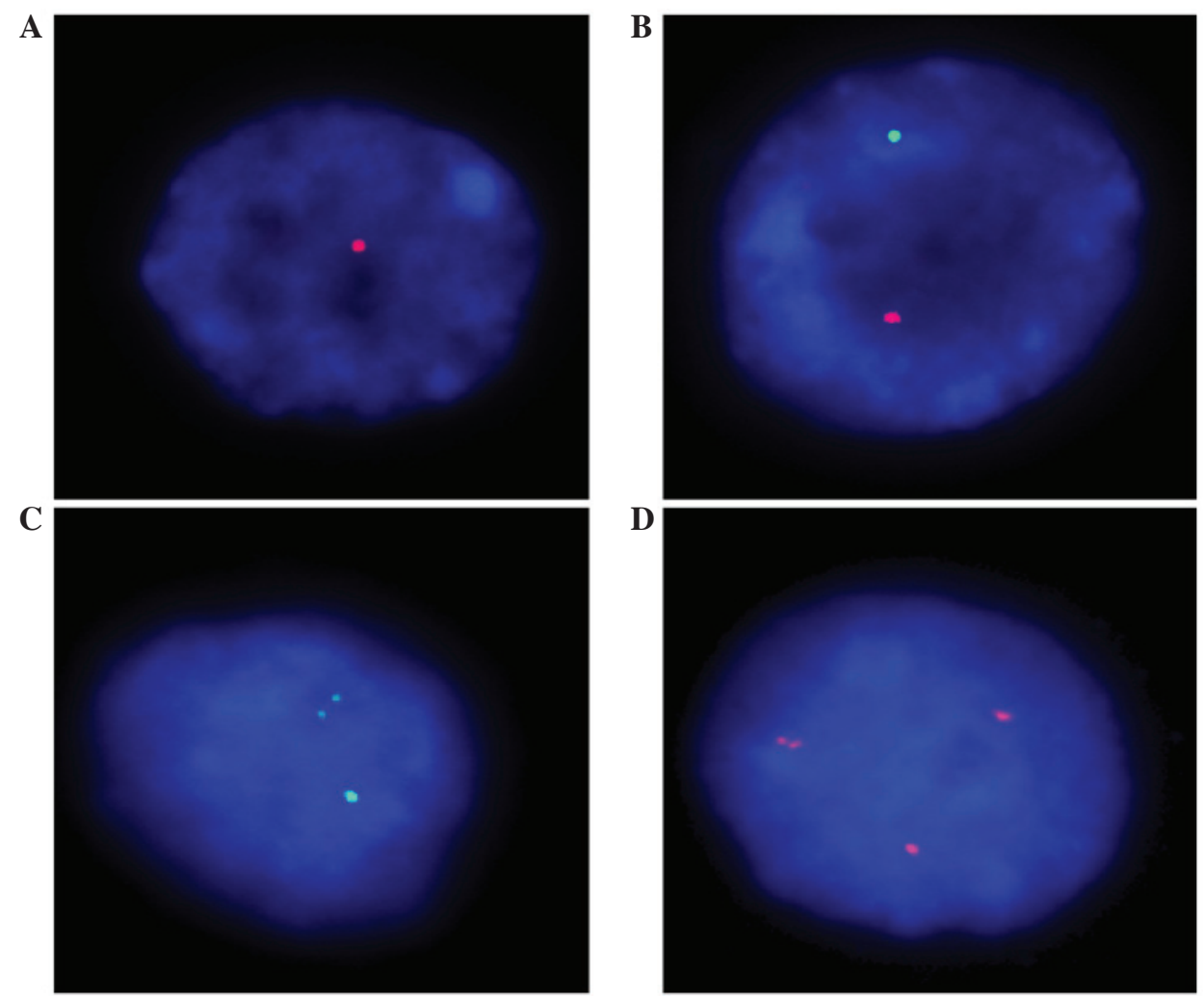

Figure 1. Detection of the genetic copy number and gene structure alterations of HER family genes using fluorescence in situ hybridization. (A) Single copy deletion of HER4. (B) Single copy deletions of HER2 and chromosome 17 centromere were confirmed. (C) Break-apart rearrangement probe in one allele was observed in the HER3 gene. (D) Break-apart rearrangement probe and amplification of the HER1 gene were observed. HER, Erb-B2 receptor tyrosine kinase.

In each experiment a minimum of 150 interphase nuclei were analyzed.

Statistical analysis. Statistical analyses were performed using the SPSS statistical package (version 17.0; SPSS, Inc., Chicago, IL, USA). The Spearman's rank correlation coefficient was calculated in order to evaluate the association between the loss of HER2 and the copy number variation or gene structure alterations of other members of the HER family. $\mathrm{P}<0.05$ was considered to indicate a statistically significant difference.

\section{Results}

FISH analysis. At least 150 nuclei of fluorescent in situ signals were counted for each sample. The abnormalities, including copy number variations and gene structure alterations, were 
Table IV. P-values indicating the correlations between genetic alterations as determined using Spearman's rank correlation coefficient.

\begin{tabular}{|c|c|c|c|c|c|c|c|c|c|}
\hline \multirow[b]{2}{*}{ Gene } & \multicolumn{3}{|c|}{ HER2 } & \multicolumn{3}{|c|}{ HER3 } & \multicolumn{3}{|c|}{ HER4 } \\
\hline & Loss & Amplification & Break-apart & Loss & Amplification & Break-apart & Loss & Amplification & Break-apart \\
\hline \multicolumn{10}{|l|}{ HER 1} \\
\hline Loss & 0.605 & 0.584 & 0.531 & 0.513 & 0.136 & 0.427 & 0.357 & 0.229 & 0.346 \\
\hline Amplification & 0.276 & 0.620 & 0.780 & 0.514 & 0.058 & 0.547 & $0.013^{\mathrm{a}}$ & $0.004^{\mathrm{a}}$ & 0.179 \\
\hline Break-apart & 0.910 & 0.260 & 0.431 & 0.376 & 0.639 & 0.180 & 0.349 & 0.312 & 0.299 \\
\hline \multicolumn{10}{|l|}{ HER 2} \\
\hline Loss & - & - & - & 0.309 & 0.075 & 0.293 & $0.019^{\mathrm{a}}$ & 0.111 & 0.872 \\
\hline Amplification & - & - & - & 0.130 & 0.919 & $0.005^{\mathrm{a}}$ & 0.670 & 0.617 & 0.483 \\
\hline Break-apart & - & - & - & 0.078 & 0.113 & 0.651 & 0.195 & 0.263 & 0.940 \\
\hline \multicolumn{10}{|l|}{ HER3 } \\
\hline Loss & - & - & - & - & - & - & 0.691 & 0.863 & 0.771 \\
\hline Amplification & - & - & - & - & - & - & 0.067 & 0.083 & 0.851 \\
\hline Break-apart & - & - & - & - & - & - & 0.851 & 0.863 & 0.563 \\
\hline
\end{tabular}

${ }^{\mathrm{a}} \mathrm{P} \leq 0.05$ is considered to indicate a statistically significant difference. HER, Erb-B2 receptor tyrosine kinase.

Table V. Percentage of the cell population that demonstrated chromosome 2 or 17 losses, analyzed using fluorescence in situ hybridization. In total, 28 cases were assessed from two previous publications and the present study.

\begin{tabular}{lcccr}
\hline & & & \multicolumn{2}{c}{$\%$ chromosome loss ${ }^{\mathrm{a}}$, mean (range) } \\
\cline { 3 - 5 } First author & Year published & $\begin{array}{c}\text { No. of cases } \\
\text { Ch2/CEN17 }\end{array}$ & Chromosome 2 & CEN17 \\
\hline Brunelli et al & 2010 & $11 / 11$ & $43(4-84)$ & $55(10-76)$ \\
Iqbal et al & 2000 & $6 / 4^{\mathrm{b}}$ & $60(15-89)$ & $65(40-82)$ \\
Weng et al & Present study & $11 / 11$ & $74(60-89)$ & $79(41-94)$ \\
Total & - & & $59(4-89)$ & $67(10-94)$
\end{tabular}

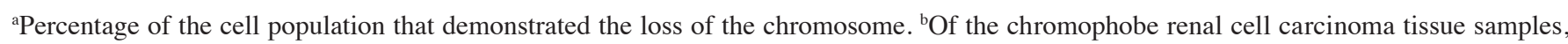
6 samples demonstrated a loss of chromosome 2, and 4 samples demonstrated a loss of chromosome 17. Ref., reference number.

identified for each gene (Fig. 1). In general, the loss of one copy of HER2 (confirmed using CEN17) and HER4 was considered to be a major alteration in all cases, and occurred in $26-97 \%$ and 60-89\%, respectively (Table III; Fig. 1A and B). However, amplifications of the HER1 gene appeared to occur more commonly in chRCC cases, at $12-35 \%$, with the exception of cases 1 and 2, which were $6 \%$. In addition, a high percentage of gene structure alterations, which were demonstrated by the break-apart alteration of probes, were also observed in the HER1 and HER3 genes, at 7-41\% and 19-30\%, respectively (Table III; Fig. 1C and D).

Statistical analysis. The Spearman's rank correlation coefficient indicated that the amplification of the HER2 gene was associated with the break-apart alteration of the HER3 gene $(\mathrm{P}=0.005)$. The loss of the HER2 gene was strongly correlated with the loss of HER4 ( $\mathrm{P}=0.019)$. In addition, the amplification of the HER1 gene was strongly negatively associated with HER4 gene loss $(\mathrm{P}=0.013)$, and positively correlated with the amplification of HER4 ( $\mathrm{P}=0.004)$ (Table IV). The amplification of HER3 was not significantly associated with the loss of HER 2 and HER4 ( $\mathrm{P}=0.075$ and 0.067 , respectively), and the amplification of HER1 ( $\mathrm{P}=0.058)$ (Table IV).

\section{Discussion}

The HER family of genes consists of four members: HER1, HER2, HER3 and HER4. The amplification of the HER1 and HER2 genes is commonly involved in a number of tumor types, including lung, colorectal and breast cancers, and may result in tumor progression, invasion and migration, and a poor prognosis (11-13). A fundamental aspect of signaling transduction in HER gene family members, with the exception of HER3, is the formation of hetero- or homodimers, and the transphosphorylation of their intracellular regions to trigger the initial signal that leads to downstream signaling activities (14). The significance of overexpression of HER2 as a predictor of breast cancer progression and prognosis has been 
previously established. Therefore, anti-HER 2 antibodies and dimerization inhibitors of other HER family receptors have been used effectively to treat breast cancer $(15,16)$.

The findings of the present study revealed that the majority of the cell populations demonstrated the loss of one copy of the HER 2 and HER4 genes, and analysis of CEN17 provided additional support for the HER2 results (Table III; Fig. 1A and B). Therefore, the findings of the present study were consistent with those of previous studies, which indicate that the downregulation of HER2 is commonly observed in RCC cells (Table V) (17-19). The various expression patterns of HER2 have been previously discussed and, in a comparison of the subtypes of RCC, the expression of HER2 was associated with the pRCC and chRCC tumor types, but not associated with tumor grade and stage (20). These findings are similar to the statistical results of the present study, which indicated that none of the clinical characteristics correlated with each other in the FISH analysis.

Despite the clinical data, the statistical analysis and interpretation of the FISH data regarding the various types of genetic alterations in the HER genes indicated that the amplification of the HER2 gene was strongly correlated with the structural rearrangement of the HER3 gene $(\mathrm{P}=0.005)$. By contrast, the loss of one copy of HER2 was significantly correlated with the loss of one allele of the HER4 gene $(\mathrm{P}=0.019)$. In addition, the amplification of the HER1 gene was strongly positively correlated with the amplification of HER4 ( $\mathrm{P}=0.004)$, and negatively associated with the loss of a HER4 allele $(\mathrm{P}=0.013)$ (Table IV). According to previous studies, the loss of chromosomes 1, 2, 6, 10, 13, 17, and 21 are considered to be cytogenetic features of chRCC (6). As HER2 is known to be located on the chromosome $17 \mathrm{q} 12$, and HER4 on chromosome 2q33.3-34, the loss of the HER2 and HER4 genes in the present chRCC tissue samples may be explained (Table III; Fig. 1A and B). However, due to the limited sample size of the present study, cases from previous studies were combined and reviewed with the present data for additional analysis. Similar phenomena, including the monosomy of chromosomes 2 (mean $\%$ of cell population, 59\%; range, 4-89\%) and 17 (mean \% of cell population, $67 \%$; range, 10-94\%) in chRCC cases were observed (Table V) $(21,22)$. At present, the strong correlation between the loss of the HER 2 and HER 4 genes $(\mathrm{P}=0.019)$ has only been observed in chRCC, and not in other subtypes of RCC; and, although the underlying reasons for chRCC cell proliferation or tumoral development remain unknown, this finding may be considered to be a valuable diagnostic or treatment marker to distinguish chRCC from other RCC subtypes.

The rearrangement of the genetic structure of the HER 1 and HER3 genes, confirmed by detecting the break-apart of probes, was observed in every tumor sample in the present study (Table III; Fig. 1C and D). Notably, the limited distance between the break-apart probe signals was observed in all cases, in various percentages of the population of cells. This finding strongly implies that the genes may harbor unknown sequences that insert into one or two alleles of the HER 1 and HER3 genes; therefore, the nucleotide sequence recombination may create chimeric fusion oncogenes, and alter the gene expression resulting in tumor induction or progression. Previous studies reported that the expression of HER 1 and HER3 may act as a predictive factor for the distant metastasis of rectal cancer (23). The overexpression of HER1 has been observed in numerous studies; however, there are no definite significant findings regarding HER 1 in RCC $(17,24,25)$. Certain reports suggested that the polyploidy and overexpression of HER 1 may be associated with RCC progression $(17,24,25)$. HER3 is known to be distinct from other HER genetic family members, as it lacks crucial amino acid residues of the kinase domain for catalytic activity; however, the overexpression of HER3 in the cell membrane was previously associated with a poor prognosis and decreased survival time in patients with head and neck squamous cell carcinoma (26). In addition, numerous studies have investigated signal transduction via HER2/HER3 dimerization, which is often described to be the most active signaling dimer. Therefore, analyzing the activities of the dimers rather than isolated markers may aid the understanding of the interactions and transduction mechanisms of the HER family.

In conclusion, one or two copies of the HER1 and HER3 genes were indicated to be inserted with an unknown gene, which may alter gene function, and result in various transduction activities. In addition, a strong correlation between the loss of the HER2 and HER4 genes may be used as a valuable marker for distinguishing the differential treatments or diagnoses of chRCC and other RCC subtypes.

\section{Acknowledgements}

The authors would like to thank the support of the National Taipei University of Technology and Mackay Memorial Hospital (grant no. NTUT-MMH-105-05), the Chang Gung Memorial Hospital (grant no. CMRPG3B1531, CMRPG380601 and CMRPG380602) and the National Science Council (grant nos. 100-2314-B-027-001 and 101-2314-B-182A-019), and Mr. Jhou Cheng-Han (National Taipei University of Technology, Taiwan, R.O.C) for formatting the paper.

\section{References}

1. Ornellas AA, Andrade DM, Ornellas P, Wisnescky A and Schwindt AB: Prognostic factors in renal cell carcinoma: Analysis of 227 patients treated at the Brazilian National Cancer Institute. Int Braz J Urol 38: 185-194, 2012.

2. Vera-Badillo FE, Conde E and Duran I: Chromophobe renal cell carcinoma: A review of an uncommon entity. Int J Urol 19: 894-900, 2012.

3. Thoenes W, Störkel S and Rumpelt HJ: Human chromophobe cell renal carcinoma. Virchows Arch B Cell Pathol Incl Mol Pathol 48: 207-217, 1985.

4. Peyromaure M, Misrai V, Thiounn N, Vieillefond A, Zerbib M, Flam TA and Debré B: Chromophobe renal cell carcinoma: Analysis of 61 cases. Cancer 100: 1406-1410, 2004.

5. Yusenko MV, Zubakov D and Kovacs G: Gene expression profiling of chromophobe renal cell carcinomas and renal oncocytomas by Affymetrix GeneChip using pooled and individual tumours. Int J Biol Sci 5: 517-527, 2009.

6. Speicher MR, Schoell B, du Manoir S, Schröck E, Ried T, Cremer T, Störkel S, Kovacs A and Kovacs G: Specific loss of chromosomes $1,2,6,10,13,17$, and 21 in chromophobe renal cell carcinomas revealed by comparative genomic hybridization. Am J Pathol 145: 356-364, 1994.

7. Yamazaki K, Sakamoto M, Ohta T, Kanai Y, Ohki M and Hirohashi S: Overexpression of KIT in chromophobe renal cell carcinoma. Oncogene 22: 847-852, 2003. 
8. Petit A, Castillo M, Santos M, Mellado B, Alcover JB and Mallofré C: KIT expression in chromophobe renal cell carcinoma: Comparative immunohistochemical analysis of KIT expression in different renal cell neoplasms. Am J Surg Pathol 28: 676-678, 2004.

9. Tan MH, Wong CF, Tan HL, Yang XJ, Ditlev J, Matsuda D, Khoo SK, Sugimura J, Fujioka T, Furge KA, et al: Genomic expression and single-nucleotide polymorphism profiling discriminates chromophobe renal cell carcinoma and oncocytoma. BMC Cancer 10: 196, 2010.

10. Weng WH, Ahlén J, Lui WO, Brosjö O, Pang ST, Von Rosen A, Auer G, Larsson O and Larsson C: Gain of 17q in malignant fibrous histiocytoma is associated with a longer disease-free survival and a low risk of developing distant metastasis. Br J Cancer 79: 720-726, 2003.

11. Ross JS, Fletcher JA, Bloom KJ, Linette GP, Stec J, Symmans WF, Pusztai L and Hortobagyi GN: Targeted therapy in breast cancer: The HER-2/neu gene and protein. Mol Cell Proteomics 3 : 379-398, 2004

12. Shia J, Klimstra DS, Li AR, Qin J, Saltz L, Teruya-FeldsteinJ, Akram M, Chung KY, Yao D, Paty PB, et al: Epidermal growth factor receptor expression and gene amplification in colorectal carcinoma: An immunohistochemical and chromogenic in situ hybridization study. Mod Pathol 18: $1350-1356,2005$

13. Grob TJ, Kannengiesser I, Tsourlakis MC, Atanackovic D, Koenig AM, Vashist YK, Klose H, MarX AH, Koops S, Simon R, et al: Heterogeneity of ERBB2 amplification in adenocarcinoma, squamous cell carcinoma and large cell undifferentiated carcinoma of the lung. Mod Pathol 25 1566-1573, 2012.

14. Sergina NV and Moasser MM: The HER family and cancer: Emerging molecular mechanisms and therapeutic targets. Trends Mol Med 13: 527-534, 2007.

15. Ross JS and Fletcher JA: The HER-2/neu oncogene in breast cancer: Prognostic factor, predictive factor, and target for therapy. Stem Cells 16: 413-428, 1998.

16. Nahta R and Esteva FJ: HER2 therapy: Molecular mechanisms of trastuzumab resistance. Breast Cancer Res 8: 215, 2006.

17. Weidner U, Peter S, Strohmeyer T, Hussnätter R, Ackermann R and Sies H: Inverse relationship of epidermal growth factor receptor and HER2/neu gene expression in human renal cel carcinoma. Cancer Res 50: 4504-4509, 1990.
18. Latif Z, Watters AD, Bartlett JM, Underwood MA and Aitchison M: Gene amplification and overexpression of HER2 in renal cell carcinoma. BJU Int 89: 5-9, 2002.

19. Thomasson M, Hedman H, Junttila TT, Elenius K, Ljungberg B and Henriksson R: ErbB4 is downregulated in renal cell carcinoma - a quantitative RT-PCR and immunohistochemical analysis of the epidermal growth factor receptor family. Acta Oncol 43: 453-459, 2004

20. Seliger B, Rongcun Y, Atkins D, Hammers S, Huber C, Störkel S and Kiessling R: HER-2/neu is expressed in human renal cell carcinoma at heterogeneous levels independently of tumor grading and staging and can be recognized by HLA-A2.1-restricted cytotoxic T lymphocytes. Int J Cancer 87: 349-359, 2000.

21. Brunelli M, Delahunt B, Gobbo S, Tardanico R, Eccher A, Bersani S, Cossu-Rocca P, Parolini C, Balzarini $\mathrm{P}$ Menestrina F, et al: Diagnostic usefulness of fluorescent cytogenetics in differentiating chromophobe renal cell carcinoma from renal oncocytoma: A validation study combining metaphase and interphase analyses. Am J Clin Pathol 133: 116-126, 2010.

22. Iqbal MA, Akhtar M, Ulmer C, Al-Dayel F and Paterson MC: FISH analysis in chromophobe renal-cell carcinoma. Diagn Cytopathol 22: 3-6, 2000.

23. Ho-Pun-Cheung A, Assenat E, Bascoul-Mollevi C, Bibeau F, Boissière-Michot $\mathrm{F}$, Cellier $\mathrm{D}$, Azria $\mathrm{D}$, Rouanet $\mathrm{P}$, Senesse $\mathrm{P}$, Ychou M and Lopez-Crapez E: EGFR and HER3 mRNA expression levels predict distant metastases in locally advanced rectal cancer. Int J Cancer 128: 2938-2946, 2011.

24. Yao M, Shuin T, Misaki H and Kubota Y: Enhanced expression of c-myc and epidermal growth factor receptor (C-erbB-1) genes in primary human renal cancer. Cancer Res 48: 6753-6757, 1988

25. Moch H, Sauter G, Gasser TC, Bubendorf L, Richter J, Presti JC Jr, Waldman FM and Mihatsch MJ: EGF-r gene copy number changes in renal cell carcinoma detected by fluorescence in situ hybridization. J Pathol 184: 424-429, 1998

26. Takikita M, Xie R, Chung JY, Cho H, Ylaya K, Hong SM, Moskaluk CA and Hewitt SM: Membranous expression of Her3 is associated with a decreased survival in head and neck squamous cell carcinoma. J Transl Med 9: 126, 2011. 